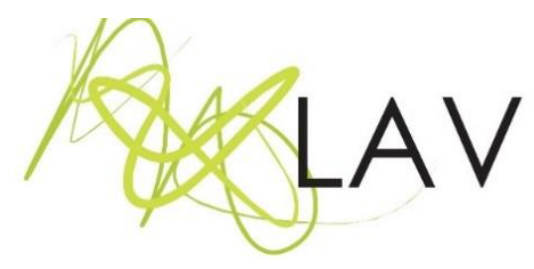

\title{
Reflexões entre pesquisa e experiência biográfica na formação de arte- educadores
}

Reflections between research and biographical experience in the formation of art educators

Lilian Ucker Perotto ${ }^{i}$ Universidade Federal de Goiás

\section{Resumo}

Neste artigo reflito sobre uma proposta pedagógica que venho desenvolvendo em uma disciplina do Curso de Licenciatura em Artes Visuais da FAV-UFG, que tem como foco conectar a experiência biográfica dos estudantes aos projetos de pesquisa que eles desenvolvem como conclusão de curso. Para este artigo narro, como nasce e se desenvolve, a proposta de vincular a experiência biográfica à formação destes estudantes, e como se torna, finalmente, um instrumento reflexivo das suas trajetórias no curso. A seguir, apresento as estratégias que são utilizadas durante a disciplina e, que, a partir da reflexividade crítica, permitem que estes estudantes se posicionem, tanto emocionalmente quanto criticamente, na construção de suas narrativas. Por fim, compartilho minha percepção sobre a experiência vivida na disciplina, lançando um olhar crítico e provisional sobre ela.
\end{abstract}

Palavras-chave: experiência biográfica, pesquisa narrativa, reflexividade crítica, ensino das artes visuais.

\begin{abstract}
In this article I reflect on a pedagogical proposal that I have been developing in an academic discipline of the Teaching Degree in Visual Arts of the FAV-UFG, which focuses on connecting the students' biographical experiences to the research projects that they develop as a course conclusion. For this article I narrate how the proposal of linking biographical experience to the formation of these students is born and developed and how it finally becomes a reflective instrument of their trajectories in the course. Following it, I present the strategies that are used during the discipline and, departing from the critical reflexivity, allow these students to position themselves both emotionally and critically in the construction of their narratives. Finally, I share my perception about this experience in the discipline by casting a critical and provisional glance at it.
\end{abstract}

Keywords: biographical experience, narrative research, critical reflexivity, visual arts teaching. 
Foi em 2007, quando iniciava meus estudos de doutorado, que tive pela primeira vez em minhas mãos o texto que transformaria minha relação com o conhecimento e, consequentemente, com minha prática docente. Relatos de Experiência e Investigação Narrativa de F. Michael Connelly e D. Jean Clandinin (1995) chegou até mim quando definia meu tema de investigação e, por isso, foi fundamental na construção do meu objeto de estudo, que se dirigia a estudar e compreender como se constitui o sentido de ser estudante brasileiro, em Barcelona. Este texto trouxe as primeiras concepções sobre o que era pesquisa narrativa e as consequências de pensar o conhecimento desde um marco epistemológico de investigação que considera a experiência humana seu tema central.

Costumo dizer que fui me tornando uma pesquisadora narrativa a partir da contribuição destes autores (PEROTTO, 2016). Mesmo estando sempre alinhada ao enfoque da pesquisa qualitativa através de metodologias orientadas a compreensão de fenômenos das práticas sociais, não "imaginava" que a experiência de ser, e mais, especificamente, que relatos (auto)biográficos, poderiam ser "objeto" de uma investigação. Pouco a pouco fui aprendendo que para se ter acesso "ao particular, temporal, subjetivo e variável das experiências humanas[...]" (CONTRERAS; PEREZ DE LARA, 2010, p. 16), era preciso repensar a ideia de que a experiência estaria vinculada a ausência da razão, com o concreto, ou ainda com aquilo que deve ser superado (CONTRERAS; PEREZ DE LARA, 2010, p. 16). Mas também foi tempo de aprender que o conhecimento científico podia se organizar através de dois modos (BRUNER, 1986): o narrativo e o paradigmático. Enquanto um está baseado no estudo científico da conduta humana através de procedimentos determinados pela tradição positivista, o narrativo é elaborado através de métodos hermenêuticos-narrativos e/ou interpretativos, porque representa o conhecimento prático, que, como afirma Polkinghorne (1988, p. 159), "aprofunda e aumenta a compreensão da experiência humana".

Foi a partir deste modo, o narrativo, que minhas experiências passaram a ser (re)inventadas, e por isso, (re)elaboradas a partir de saberes produzidos pela experiência de ser e estar no mundo. Por um lado, minha pesquisa de doutorado me permitia ampliar leituras, observar e compreender a realidade desde os significados de quem a produzia, os estudantes brasileiros. Um modo de pensar e olhar que como explica Creus (2011, p.100) "está definido menos pelos padrões do que pelas descontinuidades, menos em explicações lógicas que na lógica das emoções, menos pela dimensão estrutural dos fenômenos sociais que pelo caminho que são experienciados, vividos e significados pelas pessoas". Enquanto avançava na pesquisa de doutorado, percebi que tais aprendizagens iam, silenciosamente, 
contaminando a sala de aula e a proposta formativa da qual eu e os estudantes estávamos vinculados, onde nossos saberes biográficos iam pouco a pouco tornando-se também objeto de nossas discussões.

Quando recebi o convite para submeter um artigo ao dossiê "Narrativas afetivas de professores de artes: experiências poéticas e educação docente" pensei que seria uma ótima oportunidade, compartilhar a proposta que venho desenvolvendo na disciplina de Trabalho de Conclusão de Curso do curso de Licenciatura em Artes Visuais da FAV-UFG, que tem como foco conectar a experiência biográfica dos estudantes aos projetos de pesquisa que eles desenvolvem como requisito para a obtenção do título de licenciado em artes visuais. Para este artigo contarei como nasce e se desenvolve a proposta de vincular a experiência biográfica à formação destes estudantes na disciplina e como se torna, finalmente, um instrumento de reflexão das suas trajetórias no curso. A seguir, narro quais estratégias didáticas são utilizadas para que tal proposta favoreça os objetivos esperados inicialmente no plano de ensino e, por fim, compartilho minha percepção sobre a experiência vivida na disciplina, lançando um olhar crítico e provisional sobre ela.

\section{A experiência biográfica pode ser investigada?}

Certa vez fui convidada a participar de uma banca de TCC em outra instituição de ensino superior em Goiânia. Apoiada em teóricos da perspectiva da cultura visual, o tema de pesquisa do estudante discutia a relação entre corpo e as imagens que a mídia fabricava. Assim que recebi a versão impressa do trabalho, fiz uma leitura atenta, sublinhando questões que pareciam pertinentes à problemática da pesquisa realizada pelo estudante. Ao ler seu trabalho, fiquei curiosa em conhecer sua trajetória no curso, além do porquê do interesse do estudante por tal temática. Sua justificativa destacava a relevância teórica do tema, mas não apresentava seus vínculos biográficos com o assunto. Pensei que durante sua apresentação, minhas inquietações pudessem ser respondidas, antes mesmo de que eu perguntasse. No entanto, sua fala confirmou o conteúdo que havia sido compartilhado na versão impressa. Como convidada externa, fui a primeira a dialogar com o estudante. Antes de lançar algumas perguntas, fiz uma breve explanação sobre a possível contribuição dos estudos da cultura visual ao tema que ele havia escolhido, ressaltando o papel que desempenha o sujeito na construção do olhar em relação às visualidades. A seguir, levantei à seguinte provocação: quem é você e qual sua relação com este tema? O estudante imediatamente se apresentou e explicou seu interesse pelo tema partindo da sua biografia, no entanto, ressaltou que não se sentia autorizado academicamente em escrever sobre suas experiências no texto, por isso havia escolhido utilizar o pronome de tratamento "nós" para manter um certo distanciamento.

Revista Digital do LAV - Santa Maria - vol. 11, n. 2, p. 147 - 165 - mai./ago. 2018 ISSN 1983 - 7348 http://dx.doi.org/10.5902/1983734833902 
Esta e outras inúmeras histórias fazem parte do repertório de relatos que ainda consideram as "narrativas de si" perigosa quando se trata de pesquisa científica. A perspectiva narrativa de investigação vem romper com uma concepção de racionalidade instrumental, onde métodos desde um viés positivista passam a ser questionados, porque são insuficientes na hora de captar e compreender o relato humano (HERNÁNDEZ; RIFÁ, 2011, p. 28). Bolívar, Domingo e Fernández (2011) defendem que o método biográfico-narrativo é capaz de "captar a riqueza e indeterminação das experiências, vincular o conhecimento que surge da própria ação. Permite compreender aquilo que a racionalidade lógico-formal deixa marginalizado: conceder voz a experiência do ator social com as intenções e processos sociais de quem a vive" (BOLÍVAR; DOMINGO; FERNÁNDEZ, 2011, p. 58-59). Por dirigir-se a uma natureza contextual, específica e complexa dos fenômenos socioeducativos, a pesquisa narrativa possibilita que conheçamos, desde dentro, o que pensam, sentem e como agem aqueles que compartilham seus relatos, seja como sujeitos investigados, como investigadores ou ainda aqueles que participam de um movimento do qual contar/narrar transforma práticas cotidianas (BOLÍVAR; DOMINGO; FERNÁNDEZ, 2011). Ao narrar-se, o indivíduo revela não apenas aspectos profissionais, mas também morais e afetivos, situa o contexto, reconstrói sua experiência, estabelecendo conexões coerentes entre os acontecimentos de sua vida (GERGEN, 2007, p. 155). O "eu", conforme Polkinghorne, "não é uma coisa estática ou uma substância, mas uma configuração de eventos pessoais em uma unidade histórica, que inclui não apenas o que alguém foi, mas também previsões do que vai ser" (apud BRUNER 2006, p. 124).

É importante destacar que mesmo que acompanhemos um número expressivo de pesquisas que se utilizem da perspectiva biográfico-narrativa, ainda encontramos resistência por parte da comunidade acadêmica no uso do método. Apesar do renovado interesse pela "indagação do tipo biográfico-narrativo" (ESTEBAN, 2010, p. 150) nos últimos tempos, os questionamentos sobre rigor científico e por sua vez, a veracidade e validação (HERNÁNDEZ; RIFÁ, 2011, p. 44) ainda são um dos desafios que os pesquisadores biográficos respondem ao construir seus relatos de pesquisa.

Sparkes (2002) conta no seu texto "Autoetnografia: auto-indulgência ou algo mais?" um episódio vivido durante uma reunião de conselho onde participavam também professores e membros externos com o objetivo de avaliar trabalhos de estudantes de uma universidade da Inglaterra. Neste caso, um dos membros do conselho, chamado por Sparkes (2002, p. 210), no texto como "Professor $\mathrm{y}^{\prime}$, refere-se a um dos trabalhos utilizando as seguintes palavras: "lindamente escrito, muito interessante, fascinante [...]" e "um pouco autoindulgente". Tal trabalho, conforme Sparkes (2002) era de cunho auto- 
etnográfico. Incomodado com tais palavras, Sparkes (2002, p. 210) cogita perguntar ao "professor y" não só o significado de "autoindulgente", mas por que, ao invés de utilizar tal expressão, o professor não usou termos como "autoconhecimento", "auto-respeito", "auto-sacrifício", ou "auto-luminoso". Mesmo não estando de acordo com as palavras do "professor y", Sparkes (2002, p. 214) afirma que "os escritores de auto-etnografias e narrativas de si (como qualquer outra forma de representação) precisam estar cientes de que sua escrita pode se tornar autoindulgente ao invés de autoconsciente $[\ldots]^{\prime \prime}$.

No entanto, o autor afirma que o trabalho avaliado não era um texto autoindulgente, pois incluía:

- uso de introspecção sociológica sistemática e recordações emocionais; o 'eu' vulnerável, emoções, corpo e espírito do pesquisador; a produção de histórias evocativas que criam o efeito da realidade; a celebração da experiência concreta e dos detalhes íntimos; o exame de como a experiência humana é dotada de significado; uma preocupação com consequências morais, éticas e políticas; um encorajamento de compaixão e empatia; um foco em nos ajudar a saber como viver e lidar; a caracterização de múltiplas vozes e o reposicionamento de leitores e sujeitos como coparticipantes no diálogo; a busca de uma fusão entre ciência social e literatura; a conexão das práticas da ciência social com a vida; e a representação da experiência vivida usando uma variedade de gêneros [...] (SPARKES, 2002, p. 210-211).

Hernández e Rifá (2011) também chamam a atenção para o tema do rigor científico em uma investigação de caráter autobiográfico, sugerindo a reflexividade como uma das estratégias para a validação das pesquisas biográficas-narrativas. A reflexividade pode ser compreendida como um exercício desconstrutivo que situa "as interseções entre autor, o outro, texto e mundo, e que penetra no próprio exercício representacional (MACBETH, 2001 , p. 35). A reflexividade posicional é tratada como "um exercício analítico autoreferencial" (MACBETH, 2001, p. 38) e dá ênfase aos posicionamentos subjetivos do investigador para tornar visível seus interesses e ações dentro da investigação, entrecruzando conforme o autor:

o rigor metodológico a uma subjetividade criticamente disciplinada, descentrando não apenas as sedimentações do analista, mas (reflexivamente) as do próprio campo. Em vez de "nivelar" o mundo com uma voz narrativa singular e objetivante, ele preserva e recupera a polissemia de múltiplas posições, interesses e agências nos cenários das análises (MACBETH, 2001, p. 39).

Gergen (2007) defende que o termo reflexividade é uma das inovações metodológicas emergentes dentro do paradigma da pesquisa qualitativa e seu uso como estratégia na escrita dos relatos (auto)biográficos poderia evitar, como também afirmam Hernández e 
Rifá (2011, p. 15), um tipo de "narrativa celebratória da experiência do eu". Levando em consideração que indagar-se biograficamente nos ajuda "tornar explícitos os processos de socialização [...]", e ainda "reparar e representar um conjunto de dimensões relevantes da experiência (sentimentos, propósitos, desejos, etc) que a investigação formal deixa de fora [...]. (BRUNER apud BOLÍVAR; DOMINGO, 2011, p. 6), me pergunto: como promover práticas crítico-reflexivas a partir de perspectivas que levem em consideração a experiência biográfica do estudante universitário, neste caso do futuro arte-educador?

\section{A disciplina de 'Pesquisa em Ensino de Arte' e o 'TCC' como campo para investigar as trajetórias}

Em 2010, fui convidada a escrever o material didático da disciplina de 'Pesquisa em Ensino de Arte' (HERNÁNDEZ; UCKER, 2011) do curso de Licenciatura em Artes Visuais, modalidade a distância ( $\mathrm{EaD})$, do qual eu já atuava como docente. Dedicada à pesquisa de doutorado, presumi que o foco do material seria a perspectiva narrativa-biográfica de investigação. Aliás, quando recebi o convite para escrever o material, uma das expectativas da coordenadora de curso era dar destaque a este enfoque. O convite se estendeu ao professor Fernando Hernández, que além de supervisionar minha tese (figura 01), também acompanhava um número expressivo de pesquisas que adotavam esta perspectiva metodológica. Para mim era uma experiência nova dentro do $\mathrm{EaD}$, já que seria a primeira vez em que eu estaria dedicada à docência a partir do material (figura 02) organizado por mim e pelo professor Fernando Hernández.
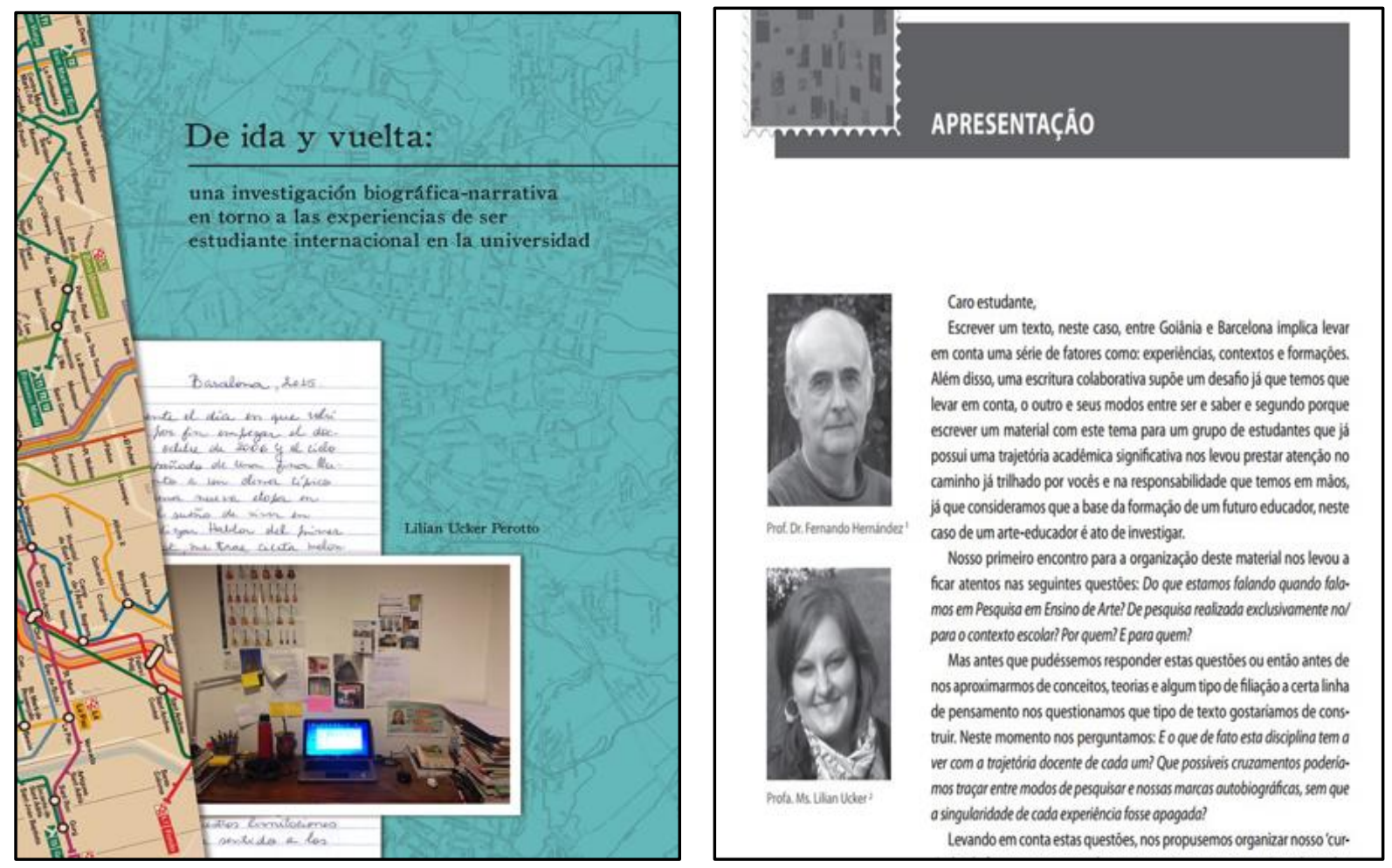

Revista Digital do LAV - Santa Maria - vol. 11, n. 2, p. 147 - 165 - mai./ago. 2018 ISSN 1983 - 7348 http://dx.doi.org/10.5902/1983734833902 
Figura 01. Capa da tese de doutorado. Figura 02. Material Pesquisa em Ensino de Arte.

Enquanto escrevíamos, eu também já vislumbrava como o conteúdo da disciplina poderia ser organizado dentro da plataforma moodle e, consequentemente, apresentado aos estudantes. Nem sempre os autores dos módulos da EaD tornavam-se os professores da disciplina. Com isso, me parecia um desafio poder organizar um conteúdo e mais tarde estudá-lo com os estudantes. Esta experiência acabou aproximando a pesquisa da minha prática docente, fazendo com que um método de pesquisa se transformasse em metodologia de ensino, cujo o foco recaia sobre a trajetória biográfica dos estudantes (PEROTTO, 2018, p. 1102).

A disciplina de Pesquisa em Ensino de Arte foi ofertada pela primeira vez em 2011 e para o primeiro grupo da Licenciatura em Artes Visuais a distância da Faculdade de Artes Visuais (UFG). Estes alunos estavam cursando o 70 semestre do curso, ou seja, já haviam percorrido um caminho significativo da sua formação. A disciplina tinha como objetivo central conhecer, compreender e analisar como o aluno da modalidade a distância representava sua trajetória/experiência no curso. Nosso interesse era saber o que haviam aprendido e como davam significado às aprendizagens. A disciplina foi planejada em diálogo com outras disciplinas, neste caso com TCC e estágio supervisionado. Ao final, os alunos produziram um capítulo do TCC onde reconstruíram sua trajetória no curso, destacando experiências das quais eles consideravam positivas e/ou negativas. As monografias trouxeram elementos críticos importantes a respeito do curso, como por exemplo, a dificuldade de acesso e navegação da plataforma moodle utilizada para o desenvolvimento das atividades nas disciplinas (PEROTTO, 2018).

Em 2012, ofertei novamente esta disciplina na modalidade a distância. Desta vez, para alunos cujo a característica principal do grupo era que todos já possuíam uma primeira graduação, além disso, uma grande parte atuava como professor nas redes municipal ou estadual de ensino. Esta oferta da disciplina exigiu mudanças já que a grade curricular era distinta do primeiro grupo. O trabalho de conclusão de curso foi a escrita de um relato autobiográfico com destaque para as relações entre as aprendizagens no curso e a prática docente destes professores-estudantes. Nosso interesse era saber o que estes professoresestudantes haviam aprendido e como tais aprendizagens ressonavam na escola.

A proposta de trabalhar a partir de perspectivas que levem a experiência e trajetória biográfica dos estudantes foi aos poucos integrando-se em meu cotidiano profissional. Da tese de doutorado, para a produção e escrita de artigos, do planejamento e desenvolvimento de disciplinas aos cargos administrativos que ocupava. Percebi que a perspectiva biográfica-narrativa, a partir da prática do contar/narrar inspirou (e inspira) outros modos de ser, de conhecer e de relacionar-me com a experiência. Narrar, narrar- 
se, contar histórias é uma boa estratégia "tanto para refletir sobre a própria identidade, como para se desidentificar de práticas realizadas em outros tempos o prefigurar o que um deseja fazer/ser" (BOLÍVAR; DOMINGO; FERNÁNDEZ, 2011, p. 62). Imersas em um processo de intercâmbio contínuo, as narrativas e autonarrativas, tal como defende Gergen (2007, p. 156), são formas sociais "de brindar explicações", mas também recursos de conversação "abertas a uma contínua alteração à medida que a interação progride".

Foi então, a partir de uma interação reflexiva, que as narrativas biográficas dos estudantes foram tornando-se dispositivos críticos para pensar a pesquisa e sua relação com os eventos da vida. Para Hernández (2011, p. 21), situar a formação docente desde perspectivas que levem em consideração a "experiência pessoal" do futuro docente "pode ter um valor de formação baseado na autoconsciência e na reconstrução narrativa da própria experiência".

Em 2014, quando decidi assumir o desafio de coordenar a disciplina de TCC, a proposta de vincular a experiência biográfica ao tema de pesquisa, ainda era bastante tímida. Eu não sabia ao certo como fazer, como organizar a disciplina e nem mesmo como iniciar o diálogo com os futuros orientadores. A disciplina de Trabalho de Conclusão de Curso na Licenciatura em Artes Visuais tem um professor responsável que coordena as ações e acompanha os estudantes nas dinâmicas de orientação. É a mim que eles recorrem quando o diálogo com o professor orientador não avança. Em outros cursos da Universidade Federal de Goiás, esta disciplina está vinculada unicamente ao orientador. Na licenciatura, eu e os estudantes nos encontramos semanalmente na universidade, cumprimos um cronograma que se estende até o final do semestre.

Muitos dos estudantes iniciam a disciplina sem um tema de TCC, outros já apresentam um cronograma com ações prévias. Entre estas situações - pesquisas a serem iniciadas e as já em andamento - o cronograma de atividades precisa ser planejado, pensando nas duas situações. A cada grupo há um novo programa formativo. Costumo levar ideias no início da disciplina para que possamos decidir juntos algumas estratégias e atividades a serem realizadas. Para este texto, estarei dedicada a contar a experiência dos dois últimos grupos, a turma do ano de 2017 e a de 2018.

Na turma 2017, éramos 18 participantes, sendo 16 estudantes, eu como professora e uma estudante do programa de pós-graduação em Arte e Cultura Visual, que nos acompanhou cumprindo seu estágio docente. Não tenho dúvidas de que a presença desta estudante impactou positivamente na dinâmica da disciplina. Naquele período, a estudante de mestrado iniciava seu trabalho em campo e, por isso, os dilemas e aprendizagens daquela 
experiência marcaram também a construção do relato de pesquisa (figura 03) dos estudantes da graduação. A vivacidade dos seus relatos, as dúvidas e as descobertas da sua força como pesquisadora, estimularam os estudantes a construírem seus percursos na pesquisa. Ambos passaram a compartilhar os mesmos dilemas, e isso os deixavam menos vulneráveis. Outro ponto de destaque na dinâmica nesta turma, é que utilizamos a metodologia da sala de aula invertida que tem como proposta romper com a chamada "sala de aula tradicional", incentivando que materiais fossem acessados/estudados/explorados antes da aula presencial. A "inversão" promove uma aprendizagem mais colaborativa, redistribuindo os papéis e responsabilidades entre professor e aluno (VALENTE, 2014). No caso desta disciplina, as aulas presenciais eram motivadas pelas atividades que iam sendo desenvolvidas na plataforma moodle a partir de fóruns de discussões, do compartilhamento de textos e imagens, da utilização de ferramentas colaborativas para análises de pesquisas de TCCs e, principalmente, da construção de diários digitais. Nesta disciplina, ao invés de adotarmos o diário em formato papel, trabalhamos com o e-diário (figura 04), assim, os alunos puderam compartilhar e aprender da experiência do outro. Os e-diários foram compartilhados no modo público, permitindo também que uns comentassem as postagens dos outros.

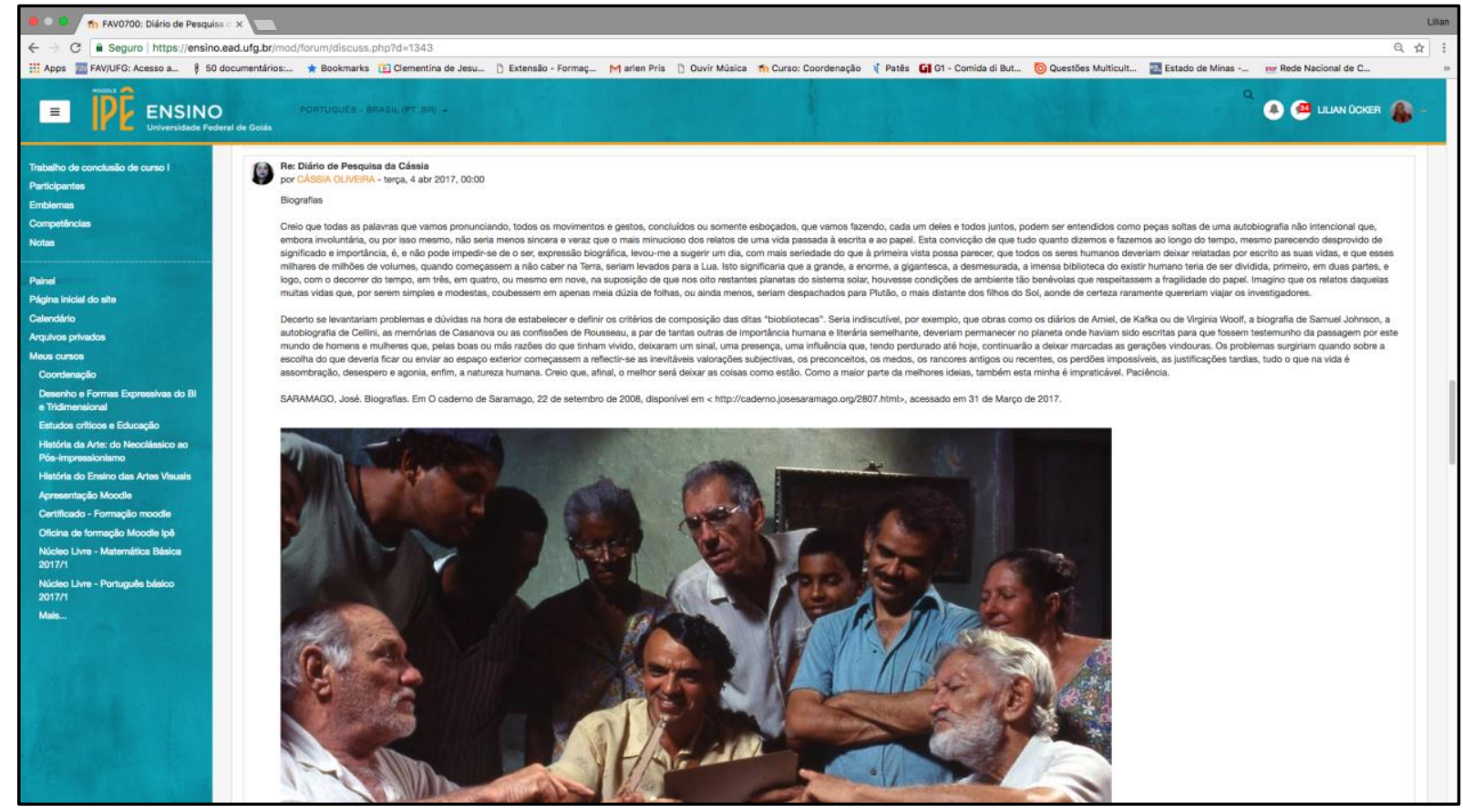

Figura 03. E-diário da Estudante do Programa de Pós-graduação em Arte e Cultura Visual

Na turma de 2018, somos 19 participantes, 18 estudantes e eu como professora. Nesta turma, a dinâmica tem sido outra. Muitos estudantes iniciaram o semestre com seus temas

Revista Digital do LAV - Santa Maria - vol. 11, n. 2, p. 147 - 165 - mai./ago. 2018 ISSN 1983 - 7348 http://dx.doi.org/10.5902/1983734833902 
e orientadores definidos. Como eles já estão construindo um diário na disciplina de estágio supervisionado, optamos por organizar um documento no drive onde eles compartilham os avanços da pesquisa. Além de poderem acompanhar os projetos dos colegas, as informações são atualizadas conforme as pesquisas vão avançando. Este 'arquivo' também foi compartilhado com os professores que orientam.

Para darmos início aos debates na disciplina, tanto em 2017 quanto em 2018, iniciamos com o texto "Uma agenda para Jovens Pesquisadores" de Marisa Vorraber Costa (2005). O texto se propõe, não só a pensar a atividade da pesquisa a partir de 12 pontos, mas também, a refletir e contribuir sobre e para a prática do pesquisador (COSTA, 2005). Além disso, a narrativa inicia com o relato de uma experiência no qual se questiona o regime da verdade defendido pela modernidade e os reflexos de tais posicionamentos para prática da ciência. Para dialogar com o texto de Costa (2005), também nos dedicamos a compreender algumas ideias apresentadas por Boaventura de Sousa Santos nos livros 'A crítica da razão indolente: contra o desperdício da experiência' (2009) e 'Um discurso sobre as ciências' (2010). O autor discursa sobre a transição epistemológica de um paradigma dominante a um emergente ou ainda de um conhecimento-regulação/emancipação para um conhecimento do senso comum solidário, participativo e ético. Além de vulgar, o conhecimento pós-moderno "é sempre contextualizado pelas condições que o tornam possível e de que só progride na medida em que transforma [...]" (SANTOS, 2009, p. 32).

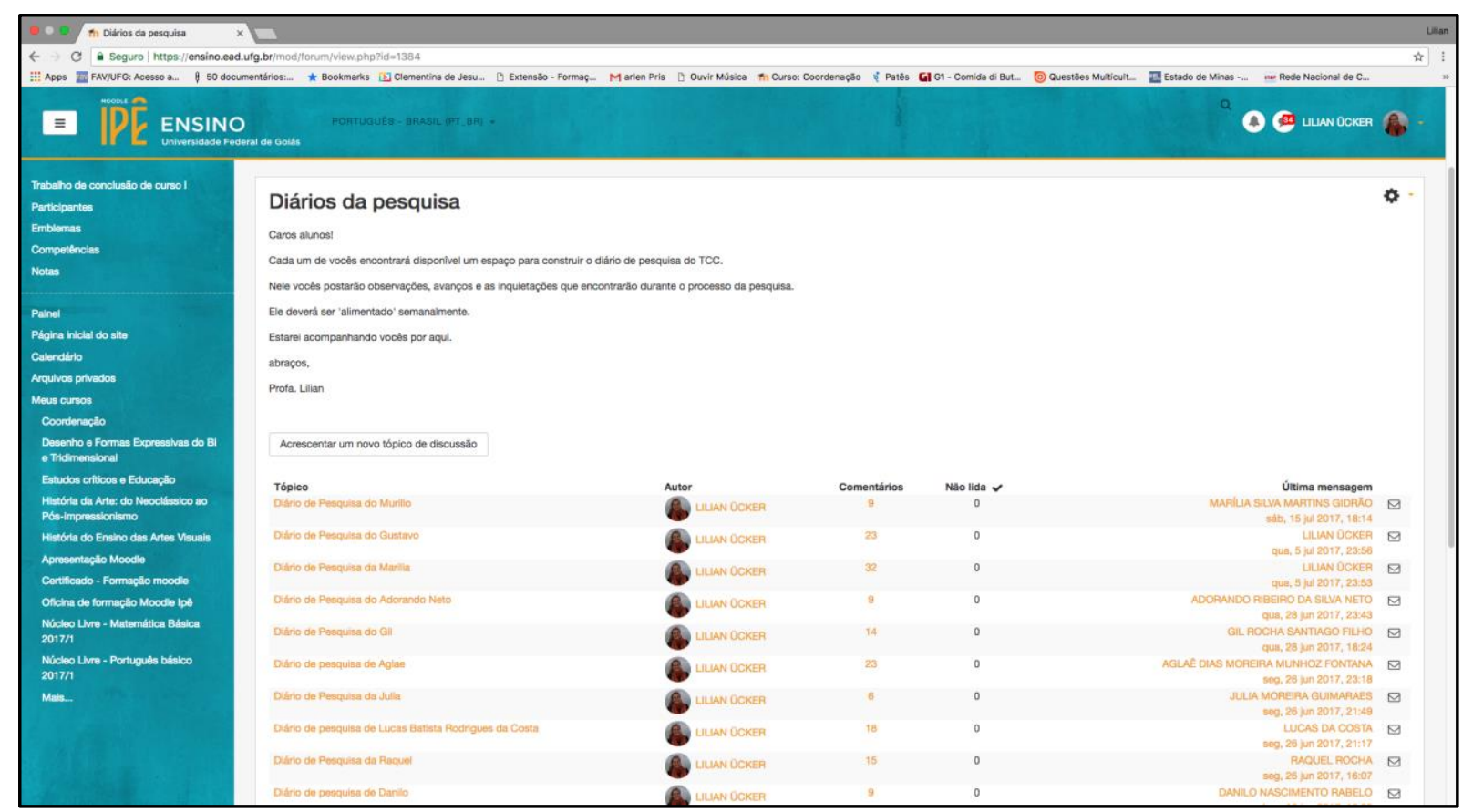

Figura 04. Plataforma digital onde os e-diários foram construídos 
Sobre o conhecimento (auto)biográfico, Santos (2009, p. 84) ainda expõe que ele é "completamente aceito" pelo paradigma emergente, é um conhecimento "compreensivo e íntimo" que nos une ao que estudamos/pesquisamos:

as nossas trajetórias de vidas pessoais e coletivas (enquanto comunidade científica) e os valores, as crenças e os preconceitos que transportam são a prova íntima do nosso conhecimento, sem o qual as nossas investigações laboratoriais ou de arquivo, os nossos cálculos ou os nossos trabalhos de campo constituiriam um emaranhado de diligências absurdas sem fio, nem pavio" (SANTOS, 2009, p. 84).

É partir da ideia defendida por Santos (2009) de que "todo conhecimento é autoconhecimento" (SANTOS, 2009, p. 81) além de que, toda investigação pedagógica "é sempre uma forma de auto-investigação" (CONTRERAS; PEREZ LARA, 2010, p. 48), que nós prosseguimos com o debate em nossa disciplina.

Um dos comentários dos professores-orientadores quando nos reunimos é que a disciplina poderia ajudar os estudantes a produzirem um capítulo dos seus TCCs. Em diálogo com os estudantes, definimos que além de estruturarmos o projeto, discutindo os tópicos da pesquisa, poderíamos nos concentrar no item 'justificativa', no 'Por que' pesquisar aqueles temas. No entanto, a justificativa deveria abarcar 4 aspectos: os teóricos, autores e pesquisas que ajudem a pensar sobre o tema e sua relevância, os sociais e políticos, quando for o caso, e os biográficos, a partir da seguinte pergunta: E o que este tema tem a ver com tua história, com tua trajetória?

\section{O exercício de narrar-se: objetos, imagens e a relação com a experiência biográfica}

Desde 2014, quando me tornei responsável pela disciplina de TCC na modalidade presencial, é comum escutar dos alunos, no início da disciplina, que não imaginavam que suas trajetórias biográficas pudessem ser objeto de estudo em uma pesquisa. Um dos primeiros questionamentos é compreender como a experiência biográfica poderá estar vinculada aos seus projetos de pesquisa. Para muitos deles a 'experiência de ser' está relacionada unicamente às emoções.

Como construir então um relato que vá além das emoções, dos sentimentos pessoais e da afirmação de si mesmo, perguntam os estudantes (e alguns professores)?

Blackman explica que raramente, na sociologia, a emoção tanto do pesquisador como dos participantes é algo explícito (BLACKMAN, 2007, p. 699). Para o autor, existe uma relutância por parte de muitos cientistas sociais em utilizarem-se das emoções na 
construção de relatos científicos. Alguns dos fatores que contribuem, e assim impedem que as mesmas sejam utilizadas como método na pesquisa sociológica, podem estar relacionados com o medo de uma possível perda de legitimidade na investigação, além da existência de uma demanda ética em que o narrador/investigador e a história/investigação, para muitos autores, "deve ser clara" (BLACKMAN, 2007, p. 700). Em muitos casos, a emoção continua sendo tratada como um saber oculto e por isso, na maioria das vezes, é "rejeitada" e considerada "inapropriada".

Rezende e Coelho (2010, p. 20) explicam que a emoção é ainda considerada, pelo pensamento da sociedade moderna, um fenômeno comum e natural a todos os seres humanos e que "a capacidade de sentir emoções resultaria do equipamento biológico e psicológico inerente à espécie humana e seria, portanto, universal". Vindo ao encontro do pensamento de Blackmam, Rezende e Coelho explicam que mesmo que o tema esteja presente nos trabalhos de muitos cientistas sociais, sua aparição se dá ainda de forma secundária, pois mesmo que considerado elemento da interação social, mantém seu "status dúbio" (2010, p.13).

Ao tratar do tema "emoção", Gergen (2010, p. 228) levanta uma importante questão: "Quem pode negar que nossas emoções são possessões privadas que pertencem ao mundo pessoal da experiência e não estão abertas a ninguém?"

No período romântico, conforme Gergen (2010, p. 228), as emoções "determinavam um respeito reverente: sua força poderia levar um sujeito a dedicar toda a sua vida a uma causa, ou a cometer suicídio". Para o modernista, as emoções "eram um incômodo, elementos que interferiam na razão e na objetividade. Não foi possível negá-los (inseridos como estavam no sistema biológico), mas sua maior esperança era que, graças à compreensão científica, pudessem ser adequadamente canalizados ou controlados para que a sociedade pudesse progredir de maneira ordenada". Já no pós-modernismo começamos a questionar estas concepções que determinavam que "as emoções eram essenciais do ser pessoal, mantidas no sistema biológico e aguardando sua expressão explosiva".

Hernandez e Rifá (2011, p. 30) sugerem a construção de relatos que 'falem desde sí" e não "de si", que significa conectar "o pessoal com as dimensões ou as forças culturais e sociais que se fazem presente no relato" e "entretejido de relatos e teoria". Tudo isso para evitar textos auto-confessionais ou ainda aqueles que são dirigidos unicamente pelas emoções, sem situar o 'eu' de forma crítica e contextualizada. 
Mesmo com a discussão dos textos antes mencionados, com o partilhamento de outras pesquisas cujo enfoque era a pesquisa (auto)biográfica, para os estudantes, o saber biográfico ainda corria "subterrânea e clandestinamente, nos pressupostos não-ditos do nosso discurso acadêmico" (SANTOS, 2009. p. 84) e, por isso, difícil de ser elaborado e logo praticado. Então, neste caso, como resgatar os posicionamentos biográficos dos estudantes para que eles pudessem produzir narrativas críticas onde as emoções e as forças sociais atuassem colaborativamente?

A estratégia adotada foi a realização do que chamamos de "exercício poético-narrativo". Com seus temas definidos, os alunos foram instigados a buscar artefatos culturais, imagens e qualquer outro objeto que os conectassem a sua experiência biográfica com o tema da sua pesquisa. Podiam ser muitos objetos, ou apenas um, podiam ser objetos inusitados. A ideia é que estes estudantes contassem uma história a partir destes objetos e imagens.

Esta ação teve como objetivo: encorajar os estudantes a refletirem sobre sua trajetória acadêmica vinculando as experiências biográficas como sujeitos no mundo; ampliar o repertório de motivações a respeito da escolha do tema para não apenas reproduzir o que teóricos dizem/escrevem; criar novas formas de representação do conhecimento e, por fim, compreender que "nossa identidade atual não é, então, um evento súbito e misterioso, mas um resultado sensível de uma história de vida" (GERGEN, 2007, p.156).

Na turma de 2017, dei início ao exercício poético-narrativo. Selecionei imagens, objetos que me ajudassem a contar uma história e que pudessem vincular a certas experiências, uma história de como eu havia chegado até aquele tema de pesquisa. Antes de iniciar, os alunos se mostraram bastante preocupados em saber se haviam realmente compreendido a proposta. Na turma de 2018, decidi fazer diferente, fui a última a apresentar, não queria influenciar os estudantes na escolha do repertório de imagens e/ou objetos. O resultado foi realmente singular entre as turmas. A turma de 2017 dispôs seus objetos e imagens no chão da sala, como eu havia feito. Estes objetos e imagens representavam explicitamente seus vínculos biográficos com as escolhas temáticas, sem a necessidade de uma elaboração narrativa complexa. Duas aulas, com duração de 4 horas cada uma, foram suficientes para que as histórias fossem contadas. No caso desta turma, pude acompanhar a finalização de seus trabalhos de conclusão. Estes estudantes apresentaram, na forma de relato escrito, suas justificativas destacando os objetos e imagens que fizeram parte do exercício poético-narrativo, relacionando-os com suas experiências biográficas. 
O grupo de 2018 inovou apresentando outros objetos como videoclipes (figura 05 e figura 06) e imagens únicas que exigiram uma organização em relação a trama da história, os personagens envolvidos e o contexto. As escolhas não pareciam óbvias e os estudantes não se manifestavam apenas emocionalmente, seus argumentos transitavam do subjetivo ao social recriando suas experiências biográficas. O exercício poético-narrativo avançou várias quintas-feiras, dia da semana em que nos encontramos, e nosso calendário teve que ser reorganizado. O próximo desafio deste grupo é colocar sobre o papel o relato realizado oralmente. Alguns estudantes já sinalizaram sua dificuldade em transpor para o papel o narrado em sala de aula. Seguiremos buscando estratégias para favorecer práticas que levem em consideração as trajetórias biográficas dos estudantes.

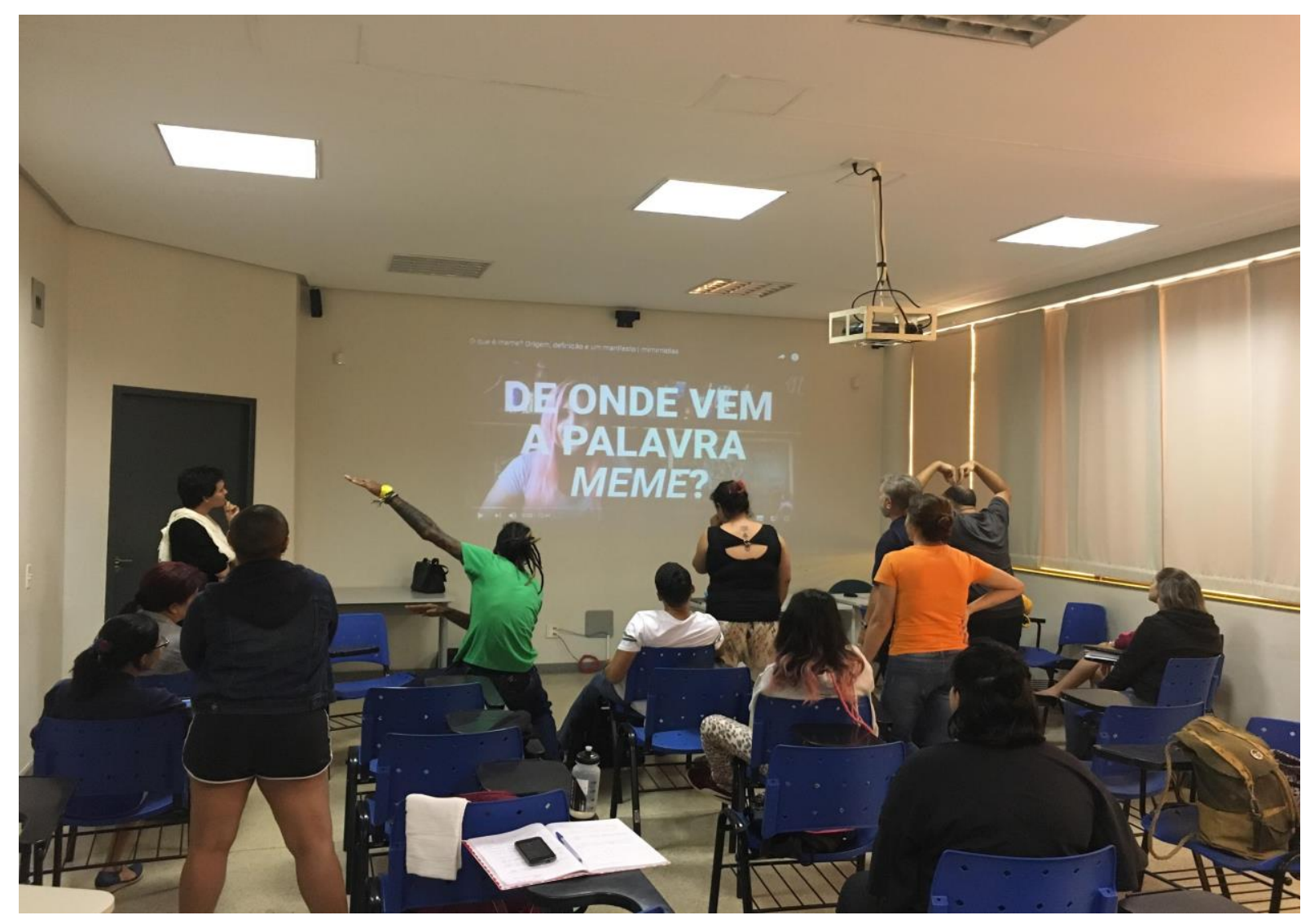

Figura 05. Estudantes realizando o exercício poético-narrativo 


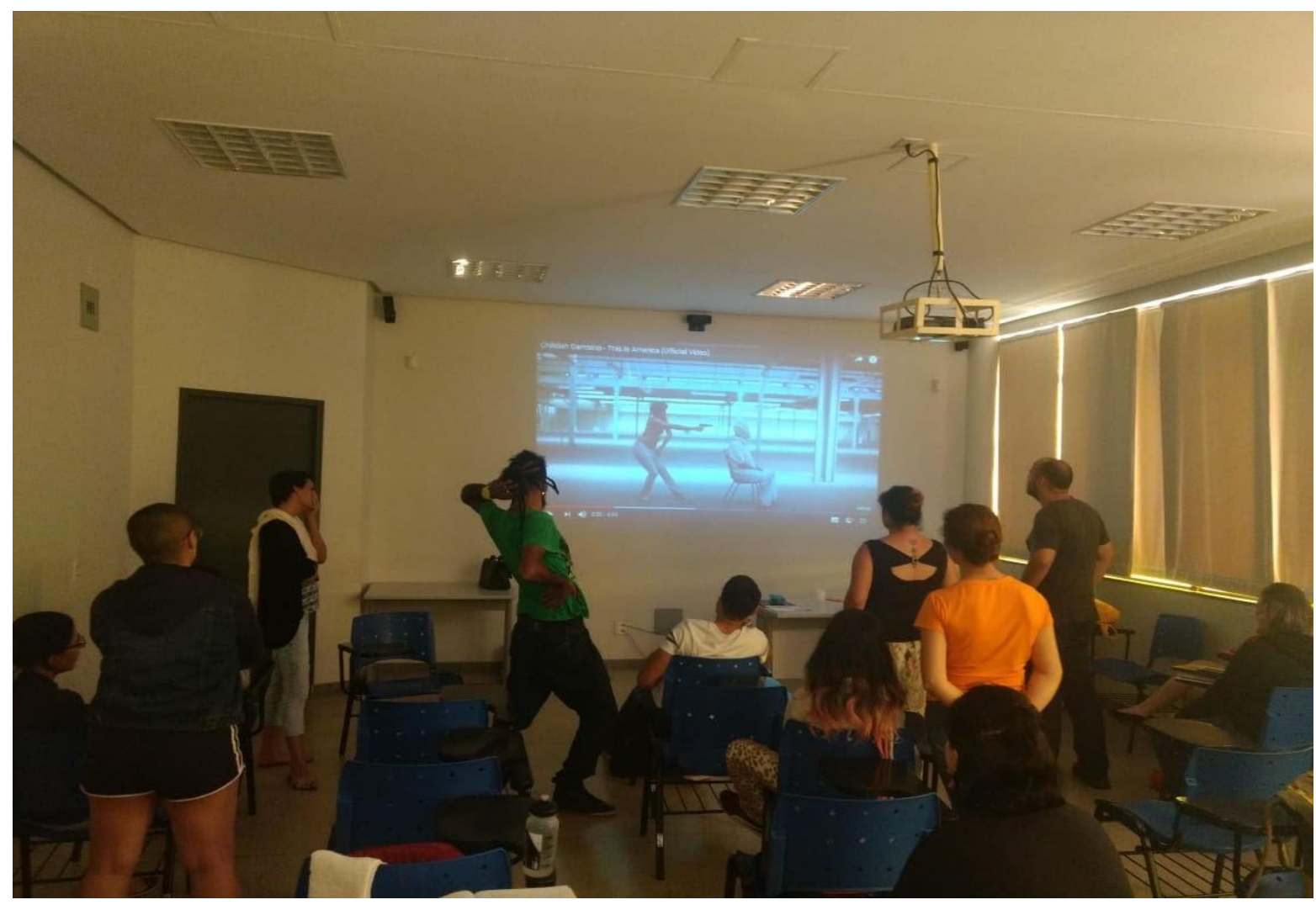

Figura 06. Estudantes realizando o exercício poético-narrativo

\section{Uma reflexão crítica (e provisional) sobre a experiência vivida}

Finalizo este texto algumas horas antes do meu último encontro com os estudantes da disciplina de Trabalho de Conclusão de Curso. Na aula de hoje, realizamos um exercício de análise de TCCs de turmas anteriores. No início da aula, comentei a eles que estava escrevendo sobre a experiência na disciplina. Para este exercício de análise, disponibilizamos trabalhos de conclusão dos anos de 2007 a 2009. Os alunos seguiram um roteiro para realizar este exercício. Alguns dos pontos que eles poderiam levar em consideração durante sua análise dizia respeito aos tópicos desenvolvidos na pesquisa, a estrutura do texto e ainda as aprendizagens, ou seja, o que aquele TCC poderia ensinar aos seus projetos de pesquisa e o que eles não gostariam de reproduzir. O exercício realizado por eles apontou fatos interessantes que nem mesmo eu havia percebido. Muitos deles observaram que a relação entre o tema e a experiência biográfica nestes TCCs foi pouco explorada, ou ainda inexistente. Curiosamente, um dos trabalhos analisados pelos estudantes foi orientado por mim. Um estudante destacou que as autoras deste TCC não relataram quem eram e qual era a proximidade com aquela temática e isso fez com que o estudante fantasiasse as escolhas, as histórias e as relações das autoras com o tema. 
Como eu havia orientado o grupo, contei a eles a relação da temática com as autoras e os desafios enfrentados por elas. Ao posicionar-se, percebi que aos poucos, aquele e outros estudantes da turma de 2018, defendiam, mesmo sem dar-se conta, a importância de trabalhar a partir desta perspectiva, do resgate da experiência biográfica para a promoção de práticas reflexivas que permitiam também refletir sobre a trajetória acadêmica vivida.

Este exercício de analisar o trabalho de outro colega permitiu que eles também se autoanalisassem. De acordo com Santos (2009, p.17) "a auto-reflexividade é a atitude de percorrer criticamente o caminho da crítica" e esta atitude, defende o autor, "é particularmente crucial quando o caminho é a transição paradigmática porque, no caso corre sempre o risco de estar mais perto do paradigma dominante e mais longe do paradigma emergente do que supõe". A reflexividade como um meio que age sobre a consciência do investigador, faz com que ele revele suas ações e emoções e, consequentemente, reflita sobre as decisões tomadas na hora de escrever o seu relato e decidir os caminhos da pesquisa (FOLEY, 2002). Apesar dos estudantes assumirem o que Foley chama de reflexividade confessional, aquela que além de incorporar práticas autobiográficas, também promove "uma maneira mais intuitiva e experiencial de conhecer e narrrar" (FOLEY, 2002, p. 475), era possível perceber que essas (auto)biografias espontâneas ou em desenvolvimento (BRUNER, 2006) realizadas através do exercício poético-narrativo, iam sendo transformadas quando entravam em interação com o outro. A espontaneidade com que narravam pela primeira vez muitas das histórias, surpreendeu colegas, construindo um ambiente não só de reciprocidade, mas também de empatia que, para Foley (2002), é consequência daquele que incorpora a reflexividade confessional no relato.

Foi a partir desta interação que os estudantes compreenderam que seus relatos eram elaborados em diálogo com os relatos de outros, e que o fato do investigador utilizar sua própria voz em primeiro plano no relato de uma investigação, não significa narcisismo, mas sim uma forma autoconsciente de se conhecer e colocar-se no mundo. Trabalhar a partir desta perspectiva; "do geral para o particular"; é considerar que a nossa subjetividade é formada, e construída "com as vozes de outras pessoas" e que, portanto, escrever sobre nós mesmos ou desde nós mesmos "é uma maneira de escrever sobre esses outros e sobre os mundos que criamos/habitamos [...]" (CHRUCH apud SPARKES, 2002, p. 216).

Quando nomeio como provisional o título deste último tópico do artigo, é porque não me sinto capaz de lançar ideias conclusivas de uma experiência que parece ainda estar em plena construção. Mesmo que pareça antiga, já que a proposta começou a ser ensaiada 
em 2010, quando escrevi junto com o professor Fernando Hernández o material da disciplina de Pesquisa em Ensino de Arte, tenho a sensação que a cada início de semestre, com um novo grupo de estudantes, inicia-se o processo do zero. Não tenho dúvidas de que a proposta precisa ser revisada e avaliada constantemente. Um dos próximos passos é analisar como a experiência compartilhada na disciplina tem reverberado no trabalho final destes estudantes. Outro desafio é conhecer se esta experiência na disciplina de TCC, de resgate dos saberes biográficos, tem contribuído com a prática docente destes professores.

\section{Referências}

BLACKMAN, S. 'Hidden Ethnography': Crossing Emotional Borders in Qualitative Accounts of Young People's Lives. Sociology, v.41, n.4, p. 699-716, 2007.

BOLÍVAR, A.; DOMINGO, J.; FERNÁNDEZ, M. La investigación biográfico-narrativa en educación: enfoque y metodología. Madrid: Editorial La Muralla, 2011.

BRUNER, J. Actual minds, possible worlds. Cambridge: Harvard. University Press, 1986.

BRUNER, J. Actos de significado: más allá de la revolución cognitiva. Madrid: Editorial Alianza, 2006.

COSTA, M. V. Uma agenda para jovens pesquisadores. In: COSTA, M. V.; BUJES, M. I. E. (Orgs.). Caminhos investigativos II: outros modos de pensar e fazer pesquisa na educação, Rio de Janeiro: DP\&A, 2005. p. 139-153.

CONTRERAS, J.; PEREZ DE LARA, N. Investigar la experiencia educativa. Madrid: Morata, 2010.

CONNELLY, M.; CLANDININ, J. Relatos de experiencia e investigación narrativa. In: LARROSA, J. (Ed.). Déjame que te cuente. Ensayos sobre narrativa y educación. Barcelona: Laertes, 1995. p. 11-59.

CREUS, A. Fragmentos de un cuaderno de viaje - Una investigación 360 narrativa sobre experiencias de inmigración. 2011. 338 f. Tese (Doutorado em Arte e Educação) Faculdade de Belas Artes, Universidade de Barcelona, Barcelona. 2011.

ESTEBAN, M. P. Pesquisa Qualitativa em Educação: fundamentos e tradições. Porto Alegre: AMGH, 2010. 
FOLEY, D. E. Critical Ethnography: the reflexive turn. International Journal of Qualitative Studies In Education, v.15, n.4, p. 469-490, 2002.

GERGEN, K. Construccionismo social, aportes para el debate y la práctica. Bogotá: Universidad de los Andes, Facultad de Ciencias Sociales, Departamento de Psicología, CESO, Ediciones Uniandes, 2007.

GERGEN, K. El yo saturado. Dilemas de identidad en el mundo contemporâneo. Barcelona: Paidós Surcos, 2010.

HERNÁNDEZ, F.; RIFÁ, M. (Orgs.). Investigación autobiográfica y cambio social. Barcelona: Octaedro, 2011.

HERNÁNDEZ, F. (Org.). Aprender a ser en la escuela primaria. Barcelona: Paidós, 2010.

HERNÁNDEZ, F.; UCKER, L. Pesquisa em Ensino de Artes Visuais. In: GUIMARÃES, L. M. (Ed.), Módulo 8. Goiânia: Funape, 2011. p. 32-44.

MACBETH, D. On "Reflexivity" in qualitative Research: Two readings, and a Third. Qualitative Inquiry, v.7, n. 1, p. 35-68, 2001.

PEROTTO, L. U. A pesquisa narrativa e a reflexividade crítica como elemento autoconfrontador de uma tese doutoral. In: CONGRESSO INTERNACIONAL DE PESQUISA (AUTO)BIogrÁFICA, 7, 2016, UFMT, Cuiabá. Anais VII CIPA. Disponível em: <http://viicipa.com.br/wordpress/wp-content/uploads/2016/07/C1T A-PESQUISA-

NARRATIVA-E-A-REFLEXIVIDADE-CR\%C3\%8DTICA-COMO-ELEMENTOAUTOCONFRONTADOR-DE-UMA-TESE-DOUTORAL-completo.pdf>. Acesso em: 10 nov. 2017.

PEROTTO, L. U. Da pesquisa à docência: a experiência biográfica como instrumento de reflexão na formação de professores em artes visuais. Dispositivos y artefactos narrativas y mediaciones. In: SEMINARIO INTERNACIONAL DE INVESTIGACIÓN EN ARTE Y CULTURA VISUAL, 1, 2017, Universidad de La República. Anais eletrônicos, Montevideo: 2018. Disponível em <http://seminarioculturavisual.enba.edu.uy/archivos/Acta2017SeminarioCulturaVisual-Uruguay.pdf>. Acesso em: 15 maio 2018.

POLKINGHORNE, D. E. Narrative knowing and the human sciences. Albany: State University of New York Press, 1988. 
REZENDE, C. B.; COELHO, M. C. Antropologia das Emoções. Rio de Janeiro: Editora FGV, 2010.

SANTOS, B. de S. A crítica da razão indolente. Contra o desperdício da experiência. São Paulo: Cortez, 2009.

SANTOS, B. de S. Um discurso sobre as ciências. São Paulo: Cortez, 2010.

SPARKES, A. Autoethnography: Self-indulgence or something more? In: BOCHNER, A. P.; ELLIS, C. (Eds.), Ethnographically speaking: autoethnography, literature and aesthetics. Walnut Creek, CA: Altamira Press, 2002. p. 209-232.

VALENTE, J. A. Blended learning e as mudanças no ensino superior: a proposta da sala de aula invertida. Educar em Revista, Curitiba, n. 4, p. 79-97, 2014.

\footnotetext{
i Lilian Ucker Perotto é Professora Adjunta da Faculdade de Artes Visuais (FAV-UFG). Doutora em Arte-Educação pela Universidade de Barcelona (Espanha). Mestre em Cultura Visual (UFG). Licenciada e Bacharel em Artes Visuais (UFSM). e-mail: lilianucker@gmail.com
}

Como citar esse artigo:

PEROTTO, Lilian Ucker. Reflexões entre pesquisa e experiência biográfica na formação de arte-educadores. Revista Digital do LAV, Santa Maria: UFSM, v. 11, n. 2, p. 147-165, mai./ago. 2018. 